\title{
ELECTRONIC BALLAST FOR HPS AND HPMV LAMPS TESTING IN DIMMING MODE
}

\author{
Cláudio R. B. S. Rodrigues, Pedro G. Barbosa and Henrique A. C. Braga \\ NIMO - Núcleo de Iluminação Moderna - Universidade Federal de Juiz de Fora, Brazil \\ claudio.rodrigues@ifsudestemg.edu.br; henrique.braga@ufjf.edu.br
}

\begin{abstract}
This paper describes the analysis and design of an electronic ballast devised to drive both, high pressure sodium vapor (HPS) and high pressure mercury vapor (HPMV) lamps, in dimmed operation with no need of parameter modification. The main objective is to achieve weight and volume reduction of a public lighting components bench test equipment, used to perform basic operational tests in a Brazilian electric utility company. Specifically, the analysis, design and implementation of an electronic ballast, based on a series-parallel loaded resonant inverter, for $70 \mathrm{~W}$ HPS and $125 \mathrm{~W}$ HPMV lamps testing is presented. Experimental results from a lab prototype, performing high intensity discharge (HID) lamp tests in dimmed operation and no discharge arc instability, evidences the feasibility of the proposed ballast concerning the intended application.
\end{abstract}

Keywords - Electronic Ballast, HID Lamps, Resonant inverter, Acoustic Resonance, Dimming Operation.

\section{INTRODUCTION}

The public lighting (PL) service is usually offered by municipalities trough electric utility companies. With a good quality and well designed PL service, improvements on public security indexes and traffic can be observed, increasing population satisfaction [1].

In this context, a R\&D project, associating Universidade Federal de Juiz de Fora (UFJF) and the electric utilities of Group Energisa, has been established in order to set standardized maintenance routines and procedures of purchasing, reception and transportation of PL components [2]. In addition to these procedures, a benching test equipment has been developed to provide support on the evaluation of the components employed in the PL system (new and used ones). Figure 1 portrays the upper front and main external modules of the developed bench test equipment. It is capable to provide useful information concerning the basic operation of HID lamps adopted by the electricity company (HPS: $70 \mathrm{~W}$, $100 \mathrm{~W}, 150 \mathrm{~W}, 250 \mathrm{~W}$ and $400 \mathrm{~W}$; HPMV: $125 \mathrm{~W}, 250 \mathrm{~W}$ ${ }^{1}$ and $\left.400 \mathrm{~W}\right)$. Moreover, the equipment can also perform simple testing of electromagnetic ballasts (with an independent check of igniter, reactor and PF capacitor stages), different types of photocells and photocell receptacles.

It is interesting to notice that mercury vapor and high pressure sodium lamps constitute the main type of bulbs

Artigo submetido em 28/03/2012. Primeira revisão em 25/07/2012 Aceito para publicação em 24/08/2012 por recomendação do editor João Onofre Pereira Pinto. being employed nowadays by the Brazilian electric companies in public lighting (Table I). Although loosing importance in this area, mainly to its reduced luminous efficacy as compared to sodium lamps, mercury vapor lamps are expected to be used in the years to come. Even in European Union, this kind of lamp is allowed to be commercialized until year 2015 (when they are going to phase out according to EU directive 2005/32/EC [3]). Hence, to provide a bench test equipment which takes HPMV bulbs into consideration is still desirable.

Since 2006, the bench test equipment illustrated in Figure 1 is being employed by Energisa technical staff in 12 cities, concerning four Brazilian federative unities, and proved to be useful and suitable according to its original purposes. However, it is a heavy and bulky equipment (about $70 \mathrm{~kg}, 1 \mathrm{~m}^{2}$ front panel, $1.2 \mathrm{~m}$ height) due mainly to eight internal electromagnetic ballasts employed in the lamp test, which corresponds to around $50 \%$ of bench test equipment weight.

In order to decrease bench test equipment weight and volume, what would enable a more compact product as well as its wide-scale manufacturing and commercialization, these bulky electromagnetic ballasts could be replaced by electronic ballasts, specially designed to perform test of groups of lamps, as proposed in Figure 2. The designed ballasts must be able to drive more than one lamp (not simultaneously), what would reduce the circuitry and electro-electronics units inside the bench test equipment. It would also make equipment failure detection easier, increasing tests reliability and reducing the bench test equipment cost.

It is important to stress that the proposed electronic ballasts will replace only the electromagnetic ballasts employed for the lamp testing. The other tests performed by the bench test equipment will remain the same.

Moreover, the use of electronic ballasts allows dimming control of the lamp, i. e. operating the lamp below its rated power, thus leading to reduced power consumption during the lamp test, as well as lamp luminous flux decrement, minimizing the glare effect over equipment operator.

The acoustic resonance (AR) avoidance is addressed on the paper, since it's an important issue when working with high frequency electronic ballast's for HID lamps [5] - [10] .

This paper focuses on the design and implementation of "Ballast 1", shown in Figure 2, which is responsible to drive a $70 \mathrm{~W}$ high pressure sodium (HPS) or an $125 \mathrm{~W}$ high pressure mercury vapor (HPMV) lamp. This electronic ballast, based on a series-parallel load-resonant inverter, can be very simple and compact, while being able to perform the test of these two kinds of lamps, operating below lamp rated power, without inducing the acoustic resonance phenomenon. 


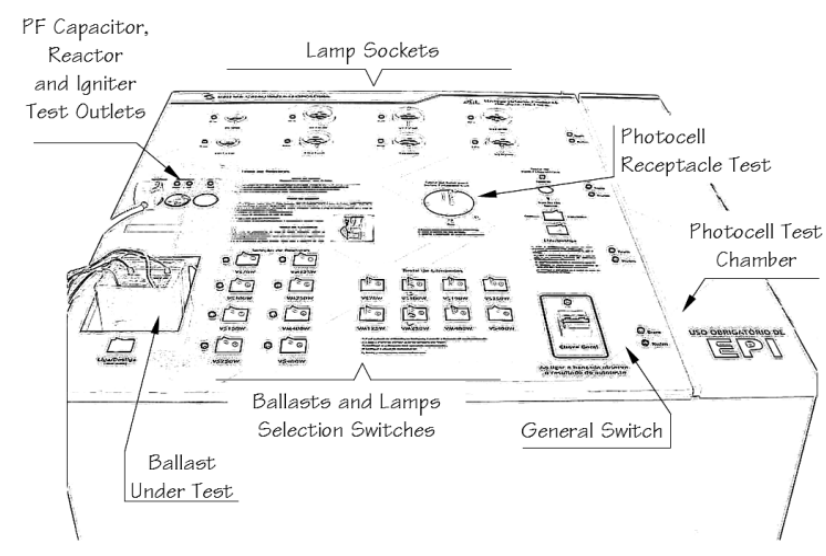

Fig. 1. Upper front view of the bench test equipment.

TABLE I

2008 distribution of lamp technologies, as employed by the Brazilian public lighting systems [4]

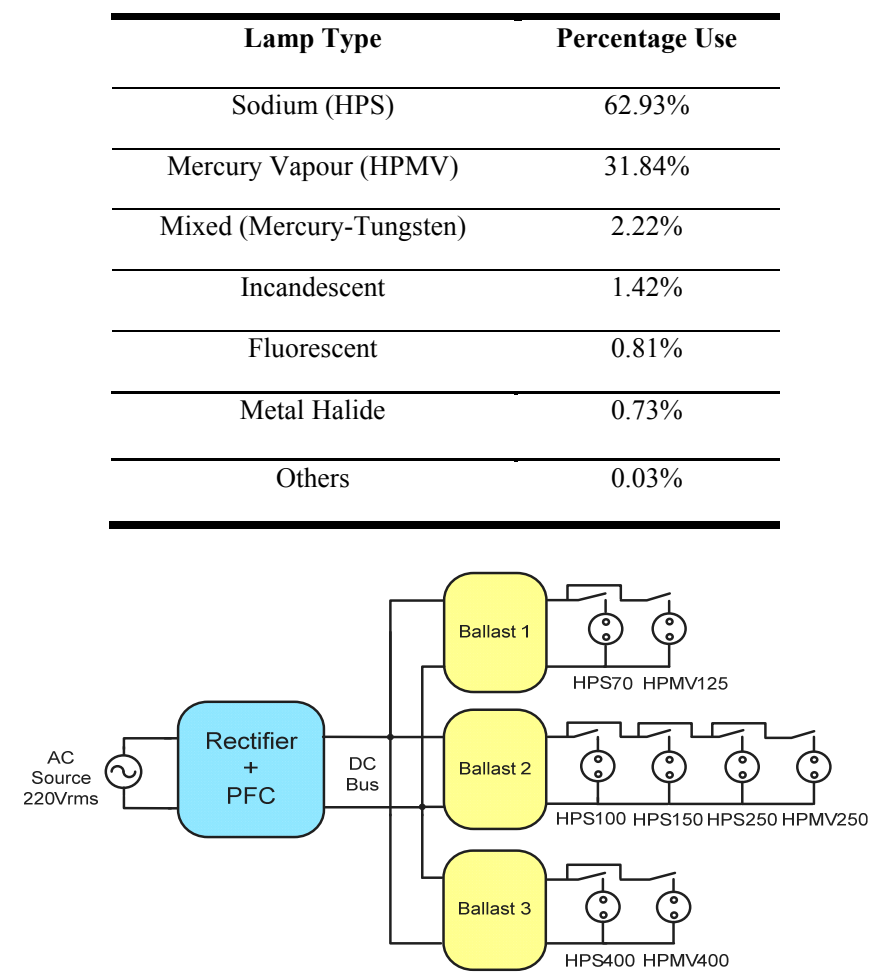

Fig. 2. Proposed ballast block diagram.

\section{ANALYSIS OF THE SERIES-PARALLEL LOAD-RESONANT INVERTER}

The proposed ballast schematic diagram is shown in Figure 3, where the high-frequency model of the lamp is represented by the resistance, $R$, while the DC voltage source, $V_{B}$, models the DC bus [11]. This circuit topology consists on a resonant inverter. This kind of circuit is usually employed in electronic ballasts for fluorescent lamps with the function of providing the rated voltage (in a quasi sinusoidal pattern) and current levels to the lamp and, in some cases, generating an overvoltage, needed to lamp ignition [12] - [14].
An inherent problem of resonant inverters is associated to switching losses, since the semiconductor devices conducts the load current and are, generally, submitted to high voltage levels. Switches turn-on and turn-off losses can represent a significant portion of power processed by the converter. This kind of losses increases linearly with switching frequency increase [15].

Nevertheless, switching losses could significantly be reduced by using soft-switching in the resonant inverter, which can be achieved imposing to the circuit a switching frequency $\left(\omega_{s}\right)$ greater than the natural oscillation frequency of the resonant filter $\left(\omega_{0}\right)$, i.e., $\omega_{s}>\omega_{0}[15]$ and [16].

Resonant inverter modeling can be performed by means of the fundamental component method [11], [15], [16] and [17], which takes into consideration only the fundamental component of $v_{0}$ (this voltage presents a $50 \%$ duty-cycle square waveform). Representing voltage $v_{0}$ by its Fourier series, it is possible to express the rms value of its fundamental component (first harmonic), $a_{1}$, as a function of the DC bus voltage:

$$
a_{1}=\frac{\sqrt{2} V_{B}}{\pi} .
$$

Moreover, the relationship between lamp voltage $\left(v_{L}\right)$ and inverter output voltage $\left(v_{0}\right)$ is described by its absolute value, according to the following transfer function:

$$
\left|\frac{v_{L}}{v_{0}}\right|=\frac{1}{\sqrt{\left[\alpha-F^{2}(\alpha-1)\right]^{2}+\left[\frac{F}{Q}-\frac{1}{F Q}\right]^{2}}},
$$

where:

$$
\begin{gathered}
\alpha=\frac{C_{s}+C_{p}}{C_{s}} \\
Q=\frac{R}{\omega_{0} L} \\
F=\frac{\omega_{s}}{\omega_{0}} .
\end{gathered}
$$

Since, in steady state, the lamp impedance is much lower than the $C_{p}$ capacitor impedance, the resonant frequency $\left(\omega_{0}\right)$, that appears in (4) and (5), is assumed to be:

$$
\omega_{0}=\frac{1}{\sqrt{L C_{s}}} .
$$

The voltage gain of a series-parallel loaded resonant inverter depends strongly on the load and raises with quality factor $(Q)$ increase, as can be seen in Figure 4. Thus, this circuit can be designed to generate the overvoltage needed to lamp ignition, since it works in an appropriated switching frequency. 


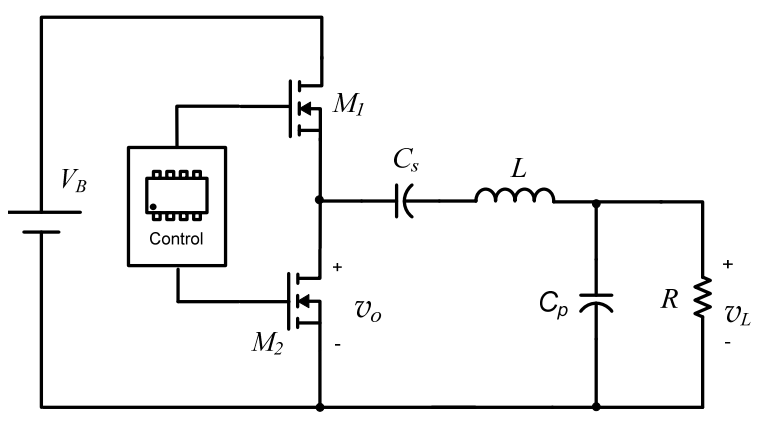

Fig. 3. Series-parallel loaded resonant inverter.

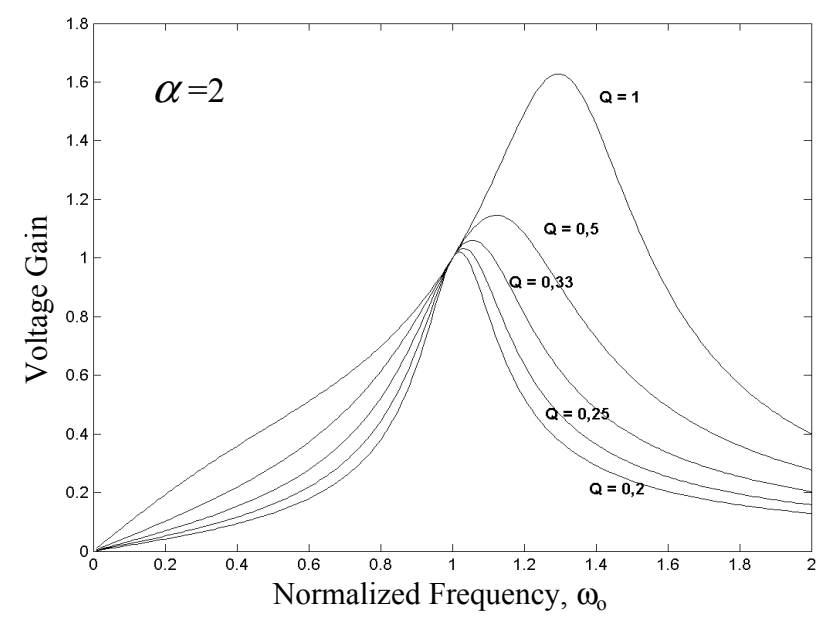

Fig. 4. Series-parallel loaded resonant inverter voltage gain $(\alpha=2)$.

\section{RESONANT INVERTER DESIGN BASICS}

The design of a resonant converter consists on choosing the reactive components $\left(L, C_{s}\right.$ and $\left.C_{p}\right)$ in order to limit lamp steady-state current and generating lamp ignition overvoltage.

The inverter switching frequency $\left(\omega_{s}\right)$ is constant during all the working stages. In order to simplify the calculation of the circuit elements, this parameter is considered, during lamp ignition, to be equal to the LCC filter resonant frequency $\left(\omega_{0 p}\right)$. The reason here is that before ignition the lamp impedance is much higher than $C_{p}$ reactance, which cannot be neglected. Hence,

$$
\omega_{s}=\omega_{0 p}=\frac{1}{\sqrt{L\left(\frac{C_{s} C_{p}}{C_{s}+C_{p}}\right)}} .
$$

After some algebraic manipulation, it is possible to obtain the components design equations:

$$
C_{p}=\frac{C_{s}}{F^{2}-1}
$$

$$
\begin{gathered}
L=\frac{F^{2}}{C_{s} \omega_{s}^{2}} \\
C_{s}=\frac{F^{2}-1}{\omega_{s} R}\left|\frac{v_{L}}{a_{1}}\right|
\end{gathered}
$$

These equations - (8), (9) and (10) - are written as functions of pre-established variables, named the inverter switching frequency $\left(\omega_{s}\right)$, the normalized frequency $\left(F=\omega_{s} / \omega_{0}\right)$, the inverter output voltage fundamental component $\left(a_{1}\right)$, the lamp equivalent resistance and the steady-state lamp rms voltage ( $R$ and $v_{L}$, respectively). The equivalent resistance is calculated, as a first approach, using the values of the rated lamp voltage (rms) and its nominal power $\left(R=V_{L}^{2} / P_{L}\right)$.

The normalized frequency $(F)$ is deeply related to lamp current harmonic distortion: low $F$ corresponds to a low THD current [12].

On the other hand, an increase in $F$ results in $C_{S}$ capacitance augmentation and also in a reduction of $L$ inductance values, which is an interesting practice to reduce the converter volume.

Finally, ballast design must take into account the lamp ignition overvoltage. According to IEC 662: the voltage level that guarantees HPS $70 \mathrm{~W}$ lamps ignition should be between $1.8 \mathrm{kV}$ and $2.5 \mathrm{kV}$ [13]. However, HPS lamp ignition, by means of an LCC resonant circuit, can be achieved with much lower voltage levels [14], [18] and [19], what is attributed to the occurrence of high frequency repetitive high voltage pulses (pulsation phenomenon) [13].

\section{BALLAST SWITCHING FREQUENCY EXPERIMENTAL DEFINITION}

One of the most delicate parameters to be defined in a high-frequency HID resonant ballast design is the switching frequency. The main idea is to ensure that the chosen switching frequency do not excite the acoustic resonance (AR). AR is a phenomenon that causes arc instability, creating low frequency fluctuations (from 0 to $20 \mathrm{~Hz}$ ), which can produce flicker, color change, electrode stress, arc extinguishing and, in extreme cases, explosion of discharge tube. It is nowadays known that AR can be excited by the operation of HID lamps at high frequencies (above some $\mathrm{kHz}$ ) [5] - [10].

Since this work goal is to design an electronic ballast capable to drive $70 \mathrm{~W}$ HPS and $125 \mathrm{~W}$ HPMV lamps, the problem of acoustic resonance is of great importance. There are some ways to prevent this phenomenon occurrence [5] [10]. In this work the method of operation within AR free windows frequencies was employed, aiming circuitry simplicity and the ignitor incorporation, what reduces the ballast volume.

To determine common AR free windows for both types of lamps, it was carried out frequency sweeping tests in several samples of some models of $70 \mathrm{~W}$ HPS and $125 \mathrm{~W}$ HPMV lamps (Philips SON PRO $70 \mathrm{~W}$, Osram VIALOX NAV - E $70 \mathrm{~W}$ and Philips HPL - N $125 \mathrm{~W})$. Using a general purpose electronic ballast available in laboratory, the lamps under test 
have been fed over a large range of frequencies (from $30 \mathrm{kHz}$ up to more than $100 \mathrm{kHz}$ ) with fixed input voltage and the arc behavior has been observed. This implies on the variation of the output power and lamp's equivalent resistance. At the end of the tests it was possible to determine some bands of frequencies in which both types of lamps did not experience arc instabilities (close to $37 \mathrm{kHz}$, close to $55 \mathrm{kHz}$ and around $70 \mathrm{kHz}$ ). The switching frequency of $37 \mathrm{kHz}$ has been chosen here, seeking to reduce switching losses. By using this selected frequency many other lamps of different manufacturers, and different operation time, of both types have been tested. Visible AR has not been observed in any case. More details about those tests can be found in [19].

\section{DOUBLE-LAMP BALLAST DESIGN}

As mentioned before, the ballast being proposed here must drive power to a $125 \mathrm{~W}$ HPMV lamp or to a $70 \mathrm{~W}$ HPS lamp in dimmed operation. As a common sense, one can argue that if the designed ballast can supply the $70 \mathrm{~W}$ lamp with reduced power, it would be expected that the $125 \mathrm{~W}$ lamp would also operate below its rated power, when driven by the same ballast with no parameter modifications. Hence, ballast design will take the Osram VIALOX NAV-E $70 \mathrm{~W}$ lamp as the reference for components calculation.

Hence, in order to achieve a reduced power operation of the sodium vapor lamp, the ballast must be designed to supply its rated power in a frequency lower than the AR free switching frequency $(37 \mathrm{kHz}$, according section IV). By doing so, i. e. operating the ballast with a frequency higher than the full power nominal frequency, the lamp will be fed with a power below its rated value. This is the preferable method of dimming arc discharge lamps. Another method consists on reducing the bus voltage, $V_{B}$, what could be more difficult in some cases, since it requires a controlled frontend rectifier.

As the difference between the full power frequency and the switching frequency increases, the lamp ignition overvoltage reachable by a given ballast reduces. So, a trade-off between power reduction and overvoltage must be established. A reduction of around 15\% in switching frequency is, then, proposed here. This leads to a full lamp power frequency of about $31 \mathrm{kHz}$, which is going to be used in the ballast design. Table II shows the main required data to make the resonant inverter components known.

TABLE II

Data required to the ballast project

\begin{tabular}{cc}
\hline Parameter & Value \\
\hline Switching frequency at full power & $31 \mathrm{kHz}$ \\
\hline Normalized frequency, $F$ & 2.7 \\
\hline DC bus voltage, $V_{B}$ & $307 \mathrm{~V}$ \\
\hline Lamp rated power, $P_{L}$ & $70 \mathrm{~W}$ \\
\hline Lamp rated rms voltage, $V_{L}$ & $71 \mathrm{~V}$ \\
\hline Equivalent resistance, $R\left(^{*}\right)$ & $72 \Omega$ \\
\hline$(*)$ low-frequency estimation
\end{tabular}

(*) low-frequency estimation
Using equations (8) to (10) and the Table II data, one can calculate the resonant filter component values finding $\mathrm{C}_{\mathrm{s}}=$ $270 \mathrm{nF}, \mathrm{C}_{\mathrm{p}}=30 \mathrm{nF}$ and $\mathrm{L}=840 \mu \mathrm{H}$.

\section{DIMMED OPERATION PROOF}

The frequency sweeping test also allows obtaining the power vs. resistance high-frequency behavior of a given lamp (a common used parameter ). This experiment has been accomplished by using the same apparatus that has been employed to study the acoustic resonance free windows (Section IV). Figure 5 and Figure 6 show, respectively, the plotting of this characteristic for an HPMV lamp (Philips HPL - N $125 \mathrm{~W}$ ) and an HPS lamp (OSRAM VIALOX $\mathrm{NAV}$ - E $70 \mathrm{~W}$ ). As can be seen, the equivalent resistance of these two lamps presents a very different behavior in relation to power variation. The HPMV lamp equivalent resistance increases with the power reduction, while the HPS lamp presents an equivalent resistance nearly constant in a power range above half rated power. This means that HPS lamps present a drastic reduction of operation voltage when power decreases, while HPMV lamps work with an almost constant voltage.

It is interesting to observe that, since there is no strict standards concerning HID lamp manufacturing, the circuit operating points can differ for lamps of different manufacturers. However, the equivalent resistance power variation characteristic presents a similar behavior, for a determined kind of lamp, even for different manufacturers.

Another important observation is that, when operating below rated power, a lamp may not present acoustic resonance in frequency ranges where the phenomenon would be excited if it was driven at full (rated) power [10].

The information of Figure 5 and Figure 6 can be used to predict lamp power in dimmed operation, if its equivalent resistance is known. This point will be clarified at following.

Before trying to prove the dimmed operation of lamps, it should be interesting to notice that, to preserve lamp lifetime, manufacturers recommend that lamps should operate at full power (for about 15 minutes) before dimming state [21]. This recommendation has not been taken into account in this work because the developed ballast application is intended for lamp testing purposes. So, at the bench test the lamp will operate in dimming mode for just a few minutes, possibly once or twice in its whole lifetime.

So, in order to preview the lamps (dimmed) power behavior when fed by the electronic ballast, as designed in Section $\mathrm{V}$, one could think of finding, at first, the ballast power behavior against output resistance. Using this characteristic in association with the characteristics of Figure 5 and Figure 6, the interception points would give the marks of interest.

By using algebraic manipulations concerning previous equations (Section II) one can find the ballast power characteristic, as given by (11).

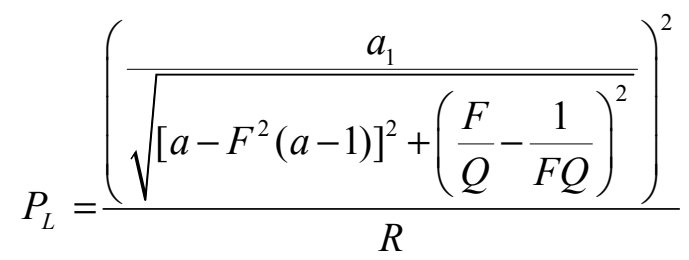


Finally, by plotting equation (11), with the resonant filter component values calculated in Section $\mathrm{V}$, against the high frequency equivalent resistance characteristics of the lamps (shown in Figure 5 and Figure 6), one can find the expected operation point of both lamps. This situation is depicted in Figure 7. Note that HPS $70 \mathrm{~W}$ lamp has been represented by a constant resistance curve of $85 \Omega$, which closely match the experimental (narrow) range observed above, say, $45 \mathrm{~W}$, in Figure 6. Hence, according to Figure 7, the reference lamps should work with the following reduced power:

- HPS: OSRAM VIALOX NAV - E 70 W (Old): 49,82 $\mathrm{W}$;

- HPMV: PHILIPS HPL N 125 W (Old): 91,69 W.

Hence, in both cases, the lamps will operate at reduced power as intended. Experimental verification is given in next section.

Concerning to the ignition, it is important to stress that HPMV lamps voltage needed is much lower than the HPS lamp ignition voltage [22], hence the proposed ballast will work properly. It is interesting to point out here that the output ballast voltage will not increase so much when a HPMV lamp is connected. It occurs because the equivalent resistance of this lamp, before the ignition, is much lower as compared to the HPS lamp since it has an auxiliary ignition electrode.

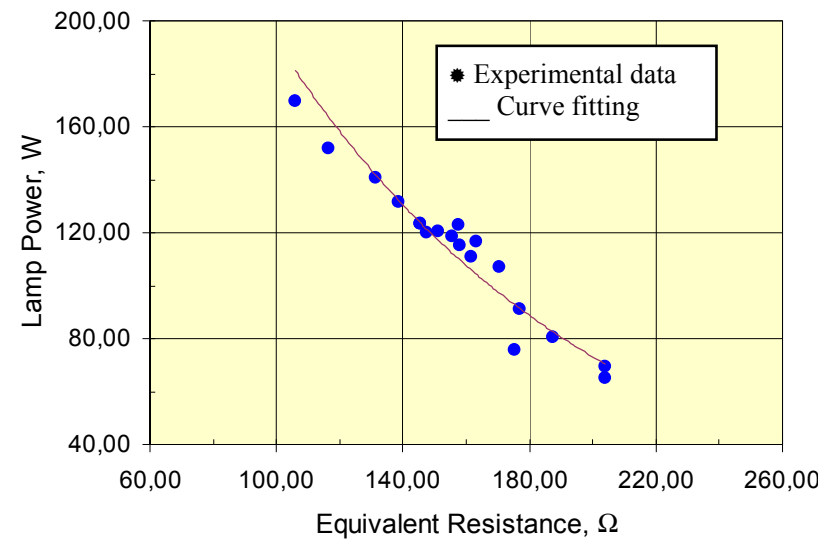

Fig. 5. 125W HPMV lamp experimental high-frequency behavior.

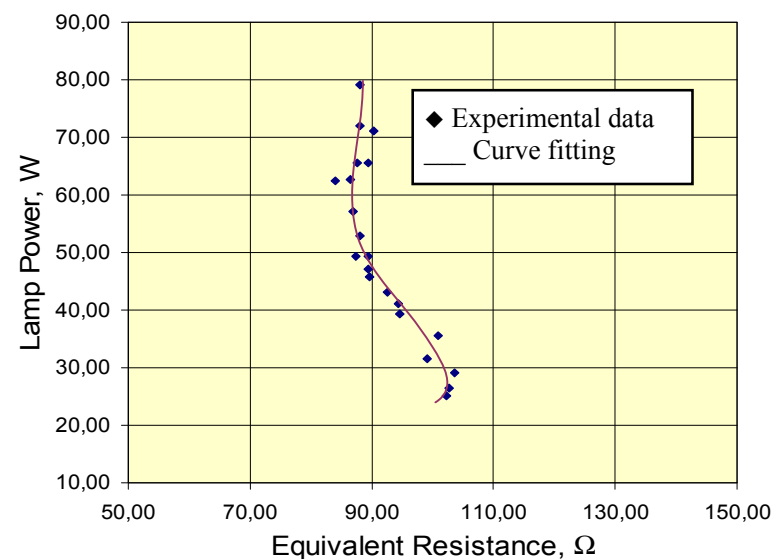

Fig. 6. 70W HPS lamp experimental high-frequency behavior.

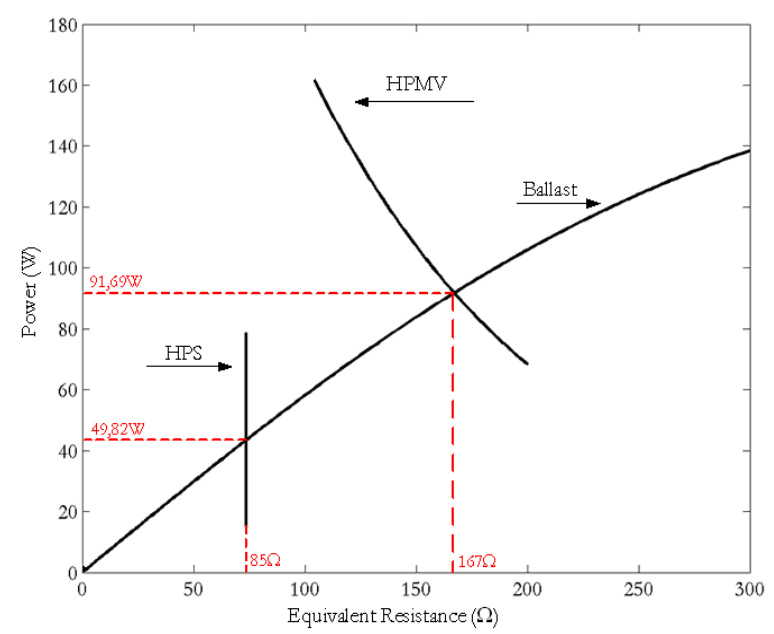

Fig. 7. Lamps operating point.

\section{EXPERIMENTAL RESULTS}

The designed ballast was prototyped, according to Figure 8 photography. Several tests, with new and old lamps, from different Brazilians manufacturers, have been performed. Table III shows some of these results. It was not possible to know the age of the old lamps employed in the lab tests, since they were obtained directly from the electric utility PL system concerning locations with no lamps time of use control. Figure 9 shows the voltage waveform oscillation of a 70 W HPS lamp before ignition.

It can also be seen that the lamp is started with a $1.15 \mathrm{kV}$ peak voltage. In addition, Figure 10 depicts the voltage and current waveforms regarding a 125 W HPMV lamp steady state operation.

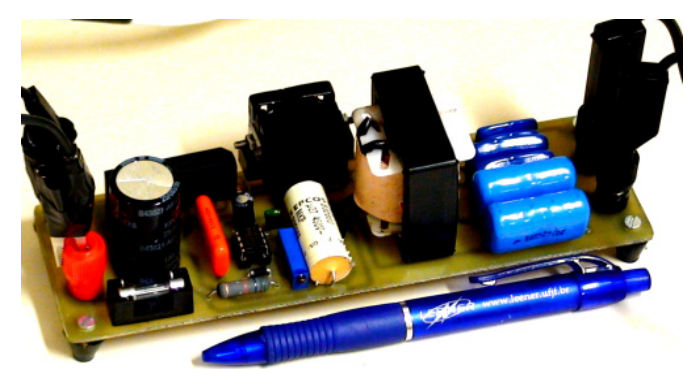

Fig. 8. Proposed electronic ballast laboratory prototype.

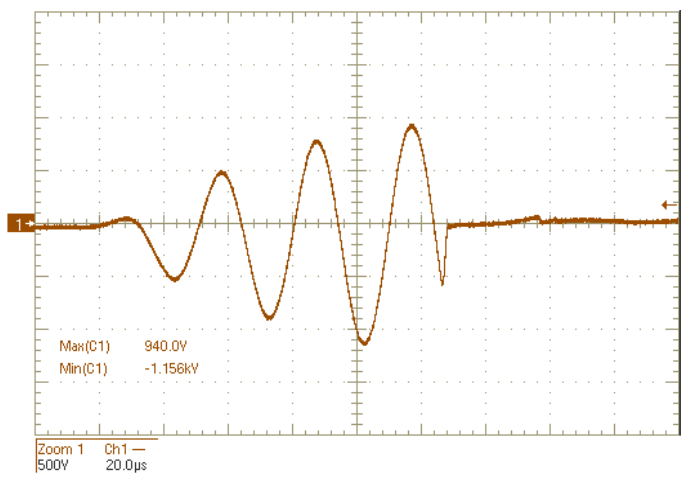

Fig. 9. HPS VIALOX NAV - E 70W lamp ignition voltage waveform $(500 \mathrm{~V} / \mathrm{div}, 20 \mu \mathrm{s} / \mathrm{div})$. 


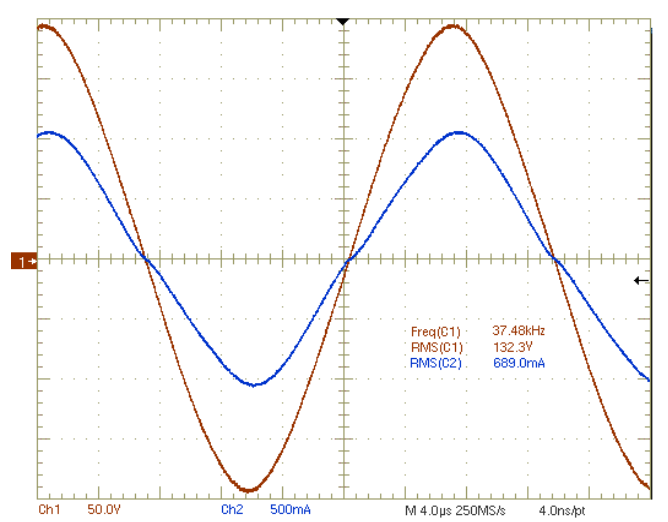

Fig. 10. HPMV HQL (new) $125 \mathrm{~W}$ lamp experimental results. Steady-state lamp voltage (brown trace, $50 \mathrm{~V} / \mathrm{div}$ ) and current (blue trace, $1 \mathrm{~A} / \mathrm{div}$ ) waveforms.

TABLE III

Experimental results

\begin{tabular}{|c|c|c|c|c|}
\hline & Lamp Type & Condition & $\begin{array}{l}\text { Ignition } \\
\text { Voltage }\end{array}$ & Power \\
\hline \multirow{5}{*}{ 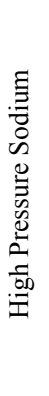 } & $\begin{array}{l}\text { VIALOX NAV - E } \\
\text { 70W (OSRAM) }\end{array}$ & NEW & $1.15 \mathrm{kV}$ & $42.98 \mathrm{~W}$ \\
\hline & $\begin{array}{l}\text { VIALOX NAV - E } \\
\text { 70W (OSRAM) }\end{array}$ & OLD & $1.15 \mathrm{kV}$ & $45.43 \mathrm{~W}$ \\
\hline & $\begin{array}{l}\text { SON 70W } \\
\text { (PHILIPS) }\end{array}$ & NEW & $1.53 \mathrm{kV}$ & $46.65 \mathrm{~W}$ \\
\hline & $\begin{array}{l}\text { SON 70W } \\
\text { (PHILIPS) }\end{array}$ & OLD & $1.15 \mathrm{kV}$ & $48.89 \mathrm{~W}$ \\
\hline & $\begin{array}{l}\text { Gold Ligth } 70 \mathrm{~W} \\
\text { (SYLVANIA) }\end{array}$ & NEW & $1.50 \mathrm{kV}$ & $40.97 \mathrm{~W}$ \\
\hline \multirow{5}{*}{ 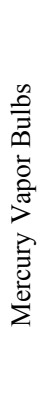 } & $\begin{array}{c}\text { HQL 125W } \\
(\text { OSRAM) } \\
\end{array}$ & NEW & --- & $80.70 \mathrm{~W}$ \\
\hline & $\begin{array}{c}\text { HQL 125W } \\
\text { (OSRAM) }\end{array}$ & OLD & --- & $82.35 \mathrm{~W}$ \\
\hline & $\begin{array}{c}\mathrm{HPL}-\mathrm{N} 125 \mathrm{~W} \\
(\mathrm{PHILIPS})\end{array}$ & NEW & --- & $86.04 \mathrm{~W}$ \\
\hline & $\begin{array}{c}\mathrm{HPL}-\mathrm{N} 125 \mathrm{~W} \\
(\mathrm{PHILIPS})\end{array}$ & OLD & --- & $90.85 \mathrm{~W}$ \\
\hline & $\begin{array}{c}\text { Deluxe White } 125 \mathrm{~W} \\
(\mathrm{GE})\end{array}$ & OLD & --- & $80.27 \mathrm{~W}$ \\
\hline
\end{tabular}

\section{A DISCUSSION REGARDING LAMPS END OF LIFE CONDITION}

The main purpose of the bench test equipment mentioned in the Introduction (Section I) is to provide the operators (engineers and electric companies' technicians) a simple tool to check basic functionalities of lighting components. This means that a sample of an acquired set of lamps should pass through the bench test when it could be verified its good condition (even new bulbs could failure in this first test, as has been observed in past acquisitions, and should be returned to vendors according to regular warranty). The other interesting occasion to test a bulb is when technicians are in doubt about used unities conditions, if they need to perform very fast maintenance in the public lighting network. In this case, sometimes the entire set of components is replaced by a new one and the used components are brought to service or bench testing at the company office or laboratory. However, simple glowing bulb results do not ensure a perfect outdoor operation (as explained at following), especially in the case of end of life condition or premature lumen depreciation. Good maintenance practices and time of use control procedures could help companies to avoid keeping unsuitable unities at field.

Nevertheless, this ideal public lighting procedures is not always observed in many municipalities and electricity companies. Hence, a technique to preview a bad on-site bulb operation would be desirable to be included in the bench test. Although it has not been designed yet, the electronic ballast described here could be associated to some kind of "end of life" automatic verification system.

Mercury vapor lamps, for example, rarely burn out completely but suffer from lumen depreciation. The lamp produces $50 \%$ less light every five years, to the point of becoming ineffective while still drawing the same amount of power it drew when it was new. It can be also observed that HPMV lamps fall to $80 \sim 75 \%$ of its original light output after only 2,000 hours. This is the result of loss of emission from the electrodes so that the arc fails to strike [22].

On the other hand, high pressure sodium lamps exhibit a phenomenon known as cycling when they are at the end of its life. These lamps can be started at a relatively low voltage but as they heat up during operation, the internal gas pressure within the arc tube rises and more and more voltage is required to maintain the arc discharge. As a lamp gets older, the maintaining voltage for the arc eventually rises to exceed the maximum voltage output by the electrical ballast. As the lamp heats to this point, the arc fails and the lamp goes out. Eventually, with the arc extinguished, the lamp cools down again, the gas pressure in the arc tube is reduced, and the ballast can once again cause the arc to strike. The effect of this is that the lamp glows for a while and then goes out, repeatedly. The cycling phenomenon is usually caused by sodium loss via chemical reactions with arc tube components (with electrode emission mix, wall material, and sealing material). Other possibility is due to an increase in amalgam temperature caused by arc tube end-darkening or an increase in electrode losses [22]. Since HPS lamps need an ignitor associated to the electromagnetic ballast (which differs from HPMV lamps), the cycling problem may result in ballast and ignitor premature failure.

The cycling phenomenon often results in a switching (lamp on and off) process with duration of several minutes, which may not be detected in a fast bench testing. So, operators should be instructed to execute the test for a minimum amount of time, say 10 minutes or more, depending on the lamp model and brand. As already mentioned here, an alternative is to provide an automatic end of life detection system associated to the ballast.

Techniques to detect end of life condition of HID lamps are not so simple and have been object of some interesting works [23] - [27]. For example, it would be possible to state that a HID bulb is at the end of its life if its steady state current presents some amount of imbalance, as in the occurrence 
of a rectification process. This situation could be measured by means of charging a well-placed detection capacitor, which would be completely discharged in the case of normal condition lamp operation [24]. Another option is to provide the lamp with a drive circuit with a zero-crossing detector, generating a voltage pulse each time a zero-crossing of the lamp current is detected. So, one could utilize the absence of such zero-crossing signals as indicating the occurrence of an end of life mode [23].

A further alternative would be to measure the terminal lamp voltage and verify if it surpasses a specific threshold, since old bulbs normally feature increased arc voltages as compared to new ones (see Table IV, where the electronic ballast voltages are relative to the dimming operation). However, due to the great variety of lamp models and brands to be tested it would be necessary to store those threshold levels in some kind of memory and ask the operator to indicate, prior to the bench test, the exact type of bulb being tested. It can be seen that, even in dimmed operation the arc voltage of the old lamps are higher than the new ones.

In conclusion, although not implemented yet, the above discussion explains that it would be possible to provide the ballast proposed here with some kind of automatic lamp end of life detection system. In this case, the maintenance procedure would become more straightforward and accurate, avoiding subjective or premature conclusions from novice technicians or not well trained bench test operators.

\section{CONCLUSIONS}

This work has proposed an electronic ballast to be applied to a bench test equipment intended for basic testing of HPS and HPMV lamps. The main idea was to achieve weight and volume reduction of the test equipment, as well as energy saving and minimization of glare over operator. On this way, the ballast has been designed to provide power to both (not at the same time), a $70 \mathrm{~W}$ sodium and $125 \mathrm{~W}$ mercury vapor lamp, in dimming operation.

Series-parallel load-resonant inverter has been chosen to be the core of the ballast and its main characteristics and equations have been revised here. A design methodology for the LCC resonant circuit has also been included.

TABLE IV

HID (Old and New) Lamps Voltage Operation

\begin{tabular}{cccc}
\hline Lamp & Condition & $\begin{array}{c}\text { Electromagnetic } \\
\text { Ballast Voltage }\end{array}$ & $\begin{array}{c}\text { Electronic } \\
\text { Ballast } \\
\text { Voltage }\end{array}$ \\
\hline $\begin{array}{c}\text { HPS Osram } \\
70 \mathrm{~W}\end{array}$ & NEW & $90.2 \mathrm{~V}$ & $55.6 \mathrm{~V}$ \\
\hline $\begin{array}{c}\text { HPS Osram } \\
70 \mathrm{~W}\end{array}$ & OLD & $94.8 \mathrm{~V}$ & $58.5 \mathrm{~V}$ \\
\hline $\begin{array}{c}\text { HPS Philips } \\
70 \mathrm{~W}\end{array}$ & NEW & $96.2 \mathrm{~V}$ & $64.1 \mathrm{~V}$ \\
\hline $\begin{array}{c}\text { HPS Philips } \\
70 \mathrm{~W}\end{array}$ & OLD & $100.3 \mathrm{~V}$ & $69.3 \mathrm{~V}$ \\
\hline $\begin{array}{c}\text { HPMV } \\
\text { Osram 125W }\end{array}$ & NEW & $119.4 \mathrm{~V}$ & $115.5 \mathrm{~V}$ \\
\hline $\begin{array}{c}\text { HPMV } \\
\text { Osram 125W }\end{array}$ & OLD & $137.3 \mathrm{~V}$ & $130.9 \mathrm{~V}$ \\
\hline
\end{tabular}

In addition, a comprehensive discussion about the definition of the inverter switching frequency has been presented. This task has been accomplished by means of frequency sweeping procedure (from $30 \mathrm{kHz}$ to $100 \mathrm{kHz}$ ) using a generic electronic ballast feeding the selected lamps, one at a time.

The sweeping frequency test has helped to find a set of frequency ranges with no acoustic resonant instabilities (ARfree windows), and the specific value of $37 \mathrm{kHz}$ has been chosen to implement the desired ballast.

Experimental results obtained from the proposed electronic ballast were used to verify the design methodology, as well the suitability of this topology to the intended application.

With no need of parameter adjustments, the lab prototype has been able to perform tests in HPS and HPMV lamps, working with reduced power and absence of visible arc instabilities. The same prototype has been also able to generate voltage spikes, as needed to HPS lamp ignition, and naturally suppressed them after this stage to enable final stages evaluation (glow to arc, warm-up and steady-state operation).

Finally, test results performed in HPS and HPMV lamps, from different manufacturers and ageing times, have been presented. All tested units have reached their steady-state operation, concerning the imposed conditions.

Moreover, a brief discussion gives some arguments that prove the possibility to predict de lamp lifetime by means of well-known techniques, although this function has not been implemented in the designed prototype.

\section{ACKNOWLEDGEMENTS}

Authors would like to recognize the invaluable financial support of CNPq, FAPEMIG, FCT/JF and Eletrobras, as well as the kind assistance of LEENER, LABEL and NIMO staff, especially the help of the electronics technician Ricardo Carvalho de Oliveira.

\section{REFERENCES}

[1] G. Casa, F. Veroni. "A New Way To Manage Public Lighting." IEEE Meeting and Tariffs for Energy Supply, no. 462, pp. 91 - 95, May 1999.

[2] M. C. B. Rodrigues, M. V. Ribeiro, S. R. Abreu, J. C. Ragone, H. A. C. Braga, D. P. Pinto, "Improvements in Public Lighting Network Management and Maintenence: Reducing Losses and Energy Waste", in Proceedings of II Congresso Brasileiro de Eficiência Energética, 2007.

[3] Osram GmbH. All change in the lighting market. Osram Lighting flyer, 2008.

[4] Procel Eletrobras. "Iluminação Pública no Brasil"; http://www.eletrobras.com/elb/procel, as accessed in February, 16th, 2011. (in Portuguese)

[5] M. A. Dalla Costa, "Compensación de Resonancias Acústicas en Lámparas de Descarga en Halogenuros Metálicos por Medio de Onda Cuadrada de Baja Frecuencia: Caracterización de Lámparas y Propuesta e Nuevas Topologías de Alimentación.” D. Sc. dissertation, Universidad de Oviedo, Gijón, Spain, 2008. (in Spanish) 
[6] M. A. Dalla Costa, J. M. Alonso, J. Ribas, J. Cardesin, J. G. Garcia, "Acoustic Resonance Characterization of Low-Wattage Metal Halide Lamps", IEEE Transactions on Plasma Science, vol. 35, pp. 43-58, 2007.

[7] J. M. Alonso, J. Ribas, M. Rico-Secades, J. García and J. Cardesín, M. A. Dalla Costa. "Evaluation of High Frequency Sinusoidal Waveform Superposed with Third Harmonic for Stable Operation of Metal Halide Lamps", IEEE Transactions on Industry Applications, vol. 41, no. 3, May/June 2005.

[8] S. Bhousle, J. B. Rouffet, D. Buso, M. Aubès, G. Zissis. "Modeling of Acoustic Resonance in HID Lamps Coupling Between Standing Waves and Arc Bending" $42^{\text {nd }}$ Industry Applications Conference, 2007 (IAS'07), Annual Meeting. New Orleans, USA, 2007.

[9] W. Yan, W., S. Y. R. Hui, "Experimental Study on Acoustic Resonance Phenomena in Ageing HighIntensity Discharge Lamps" Science, Measurement and Technology IEE Proceedings - vol. 153, no. 5, September 2006.

[10] J. C. A. Antón, C. Blanco, F. J. Ferrero, J. C. Viera, N. Bordel, A. Martín, G. Zissis, G., "An Acoustic Resonance Band Detection Workbench for HID Lamps" IEEE Transactions on Industry Applications, vol. 43, no. 5, September/October 2007.

[11] J. Melis. "Ballast Curves for HPS Lamps Operating on High Frequency." Conference Record of the 1992 IEEE Industry Applications Society Annual Meeting, vol. II, pp. 1908-1914.

[12] M. M. S. D. Perdigão, J. M. Alonso, M. A. Dalla Costa, E. S. Saraiva. "Comparative Analysis and Experiments of Resonant Tanks for Magnetically Controlled Electronic Ballasts", IEEE Transactions on Industrial Electronics, vol. 55, p. 3201-3211, 2008.

[13] A. S. André, A. J. Perín, I. Barbi. "Ignitors of Electronic Ballasts for HID Lamps ", COBEP 2001, VI Brazilian Power Electronics Conference, Florianópolis - SC vol. 2, pp. 644-649, 2001

[14] P. F. Donoso-Garcia, L. M. F. Morais, S. I. Seleme Jr.,P. C. Cortizo, "Forced Oscillation in LC Circuit Used for the Ignition of Discharge Lamps", IET Power electronics, vol. 1, p. 93-99, 2008.

[15] M. Polonskii, A. R. Seidel. Reatores Eletrônicos para Iluminação Fluorescente. Editora Unijuí, Ijuí, Brazil, 2008. (in Portuguese)

[16] R. M. Nelms, T. D. Jones, M. C. Cosby,. "A Comparison of Resonant Inverter Topologies for HPS Lamp Ballasts." IEEE Industry Applications Society Annual Meeting. IAS 93, 2-8 Oct., vol.3, pp. 2317 - 2322, 1993.

[17] W. Yan, S. Y. R. Hui. Yan Hui. "An Analysis into the Dimming Control and Characteristic of Discharge Lamps." IEEE Transaction on Power Electronics, vol. 20, Issue: 6, pp.1432-1440.

[18] S. Ben-Yaakov, M. Gulko. "Design and Performance of an Electronic Ballast for High Pressure Sodium (HPS) Lamps". IEEE Transactions on Industrial Electronics, August 1997, vol. 44, Issue: 4, pp. 486-491, 1997.

[19] C. R. B. S. Rodrigues, V. S. Lacerda, L. F. A. Guedes, H. A. C. Braga. "Design of an Electronic Ballast for two High-Pressure Mercury Lamps, $125 \mathrm{~W}$ and 250W, in
Dimmed Operation," IEEE Industry Applications Conference (INDUSCON), Aug. 2008. (in Portuguese)

[20] M. S. Perdigão, B. Baptista, J. M. Alonso, E. S. Saraiva. "Magnetic Regulator Topologies for Dimmable Electronic Ballasts." IEEE International Symposium on Industrial Electronics (ISIE 2010). Bari, Italy, pp 921 926, 2010.

[21]D. Smith, H. Zhu. "Properties of High Intensity Discharge Lamps Operating on Reduced Power Lighting Systems." Journal of the IES, vol. 22, no. 2: pp. 27-39, 1992.

[22] J. R. Coaton, A. M. Marsden. Lamps and Lighting. Arnold, $4^{\text {th }}$ Edition, London, Great Britain, 1997.

[23] J. P. E. De Krijger, M. J. M. Bucks, F. J. P. M. Seuren, E. B. G. Nijhof. Lamp driving circuit and detection circuit for detecting an end-of-life condition. United States Patent Application no. 20100026189, April, 2010.

[24] S. Venkitasubrahmanian, C. Mason, Y. Xia, F. Hu, J. Schlejen. Lamp ballast with lamp rectification detection circuitry. United States Patent No. 5808422, September, 1998.

[25] M. Moisin. Ballast having a lamp end of life circuit. United States Patent no. 6127786, March, 2000.

[26] R. E. S. Carvalho, "Projecto de um sistema para alimentação de lâmpadas HID (High Intensity Discharge) usadas em iluminação automóvel. " Master Thesis, Faculdade de Engenharia da Universidade do Porto (FEUP), Porto, Portugal, 2009 (in Portuguese).

[27] P. Dong, K. W. E. Cheng. "Compensation and Lamp Life Model of HID Lamp." $3^{\text {th }}$ International Conference on Power Electronics Systems and Applications(PESA 2009).Hong Kong pp. 1 - 3, 2009.

\section{BIOGRAPHIES}

Cláudio Roberto Barbosa Simões Rodrigues, was born in Cataguases - MG in 1980. He received the B. S. and M. S. degrees from Federal University of Juiz de Fora, in 2006 and 2009 respectively, where he is now Ph.D students. Since 2010 he is professor of the Electronic and Automation goup or Federal Institute of Education, Science and Technology of Southeast of Minas Gerais. His research interests are power electronics applied to lighting systems, electronic ballasts and drivers, public lighting, LEDs characteristics and HID lamps.

Pedro Gomes Barbosa, has a degree in Electrical Engineering from Federal University of Juiz de Fora (1986), M. S. and Ph.D. in Electrical Engineering from Federal University of do Rio de Janeiro (1994 and 2000). He is currently an associate professor at Federal University of Juiz de Fora. He has experience in Electrical Engineering with emphasis in Power Electronics, acting on the following themes: active power filters, FACTS controllers, static compensators of reactive power, voltage converters and multipulse multilevel, modeling and circuit simulation, alternative sources electricity. 
Henrique Antônio Carvalho Braga, graduated in Electrical Engineering from Federal University of Juiz de Fora (UFJF) in 1982, and acts as a teacher in this institution since 1985. He obtained a Master's degree in Electrical Engineering, COPPE / UFRJ in 1988. In 1996 completed the doctoral program at the Federal University of Santa Catarina, INEP, UFSC. He is currently a professor in the undergraduate courses and postgraduate (Masters and $\mathrm{PhD}$ ) in Electrical Engineering from UFJF, teaching courses in the area of Basic Electronics and Power Electronics. Between 2005 and 2006, Prof. Braga participated in an office of postdoctoral studies at the University of Oviedo in the Spanish city of Gijon, Asturias. Professor Braga is involved in activities related to Power Electronics, Efficient Lighting, Converters Applied to Renewable Energy and more recently the development of innovative electronics products with the CRITT / UFJF. He is a partner of SOBRAEP and served as a board member of the organization in 1995 and 1996. In 2011 he was elected Vice-President of this entity. 